\title{
Composition and Properties of Platinum-Rhodium Alloy Surfaces
}

\author{
F.C.M.J.M. van DELFT,1) B.E. NIEUWENHUYS,2) J. SIERA and R.M. WOLF
}

Gorlaeus Laboratories, Leiden University, P.O. Box 9500, 2300 RA Leiden, The Netherlands. 1) Gorlaeus Laboratories, Leiden University. Now at Philips Research Laboratories, Eindhoven, The Netherlands. $\quad 2$ ) Author to whom correspondence should be direct.

(Received on October 3, 1988; accepted in the final form on December 20, 1988)

\begin{abstract}
The use of Pt-Rh based three-way catalysts for automotive exhaust gas control stimulated us to study the surface composition and surface properties of various Pt-Rh alloy samples. In this paper we shall review our results concerning the relation of the surface structure and surface composition with the physical and chemical properties.

The surface composition was studied under various experimental conditions, both in vacuum and in the presence of an atmosphere of $\mathrm{NO}, \mathrm{O}_{2}, \mathrm{CO}$ and $\mathrm{H}_{2}$. The effect of the temperature on the surface composition will be described and discussed on the basis of thermodynamics. We shall discuss the relation of surface composition with the physical properties (Debye Temperature) and with the chemical properties of Pt-Rh alloys, in particular towards $\mathrm{NO}, \mathrm{CO}, \mathrm{O}_{2}$ and $\mathrm{H}_{2}$ and their reactions.

Another part of the paper deals with the effect of the surface structure on the chemical properties of Pt-Rh alloys. NO dissociation, the first step in the NO reduction with $\mathrm{CO}$ or $\mathrm{H}_{2}$, is extremely sensitive to both the structure and the composition of the surface.
\end{abstract}

KEY WORDS: platinum; rhodium; alloys; surfaces; nitric oxide; catalysts.

\section{Introduction}

In this introductory chapter a brief review is presented concerning the interest in the surface properties of Pt-Rh alloys. In addition, an outline of the present paper is presented.

The first interest in the understanding of the surface properties of $\mathrm{Pt}-\mathrm{Rh}$ alloys was related to the industrial application: $\mathrm{Pt}-\mathrm{Rh}$ gauze is used already for many years in two important industrial processes, viz. the production of nitric acid via the catalytic oxidation of ammonia and the HCN synthesis. Most of the nitric acid produced is used for the manufacture of nitrate fertilizers. A major problem in the production of nitric oxide is the loss of the noble metal during commercial use. This loss is related to the formation of volatile $\mathrm{Pt}$ oxides. It is known already for more than half a century that the addition of rhodium to the platinum catalyst results in a drastic reduction of the $\mathrm{Pt}$ loss combined with an improvement of the reaction selectivity and activity. ${ }^{1)}$ However, even for the $\mathrm{Pt}-\mathrm{Rh}$ catalysts direct noble metal loss accounted for about $85 \%$ of the operating costs. ${ }^{2)}$ Another problem was related to the long initial activation period of the catalyst during commercial use. ${ }^{3)}$ Much fundamental research has been devoted to these problems and to the characterization of these $\mathrm{Pt}-\mathrm{Rh}$ catalysts in general. ${ }^{1-9)}$ A short section will deal with these studies.

$\mathrm{Pt}-\mathrm{Rh}$ gauze for nitric acid production is still the major demand for both $\mathrm{Pt}$ and $\mathrm{Rh}$ in the chemical sector, including the petroleum industry (about $50 \%$ ). ${ }^{10}$ However, the over-capacity in the world fertilizer industry has led to a downturn in the pro- duction of nitric acid for nitrates thereby decreasing the demand for the $\mathrm{Pt}-\mathrm{Rh}$ gauzes.

By far the dominant and still growing usage of both $\mathrm{Pt}$ and $\mathrm{Rh}$ is the consumption of the automotive catalyst utilized for the control of air pollution by exhaust emission. In 1987 the automotive catalyst accounted already for more than $35 \%$ of the total $\mathrm{Pt}$ consumption and for $73 \%$ of the Rh consumption ${ }^{10)}$. A further increase in the demand can be expected in view of the growth in the proportion of gasolineengined cars fitted with catalytic converters. The present generation converters are based on bimetallic $\mathrm{Pt}-\mathrm{Rh}$ catalysts which are called three-way catalysts since the harmful carbon monoxide, nitrogen oxides and hydrocarbons are simultaneously converted into carbon dioxide, nitrogen and water. ${ }^{11,12)}$

The major purpose of this paper is to review the present knowledge concerning $\mathrm{Pt}-\mathrm{Rh}$ alloy surfaces in relation to the processes taking place on the three-way catalyst. One part of the paper deals with the chemical composition of well defined Pt-Rh alloy surfaces, under ultrahigh vacuum conditions and in the presence of $\mathrm{O}_{2}, \mathrm{CO}$, NO and $\mathrm{H}_{2} \cdot{ }^{13-17)}$ Another part of the paper deals with the chemical properties of well defined $\mathrm{Pt}-\mathrm{Rh}$ alloy surfaces, in particular with respect to the adsorption of $\mathrm{O}_{2}, \mathrm{CO}, \mathrm{NO}$ and $\mathrm{H}_{2}$, the reduction of $\mathrm{NO}$ and the oxidation of $\mathrm{CO}^{15-18)}$ For our studies several $\mathrm{Pt}-\mathrm{Rh}$ alloy surfaces have been used: polycrystalline foils, field emitters and various single crystal surfaces cut from a $\mathrm{Pt}_{0.25}-\mathrm{Rh}_{0.75}$ single crystal. Up to now most detailed studies have been performed on the polycrystalline foils and the (100) and (410) single crystal surfaces. Some of the results are reviewed here. 


\section{2. $\mathbf{N H}_{3}$ Oxidation}

Already in 1908 Ostwald and Brauer operated the $\mathrm{Pt}$ catalyzed process on a commercial scale. Since that time it has grown to become one of the largest tonnage output processes in the world. ${ }^{9)}$ About $70 \%$ of the nitric acid produced is used in the manufacture of nitrate fertilizers, the remainder being utilized in the production of nitrogen containing products such as plastics, explosives and dyestuffs. ${ }^{91}$

Ammonia is oxidized according to the reaction with stoichiometry:

$$
4 \mathrm{NH}_{3}+5 \mathrm{O}_{2} \rightarrow 4 \mathrm{NO}+6 \mathrm{H}_{2} \mathrm{O}
$$

Undesired nitrogen is produced according to the following stoichiometric equation:

$$
4 \mathrm{NH}_{3}+3 \mathrm{O}_{2} \rightarrow 2 \mathrm{~N}_{2}+6 \mathrm{H}_{2} \mathrm{O}
$$

The catalyst requirement for the production of nitric acid is a high selectivity for reaction (1) under reaction conditions. The reaction must be carried out at a temperature above $900 \mathrm{~K}$ under oxidizing conditions. Only a few catalysts can withstand these conditions and $\mathrm{Pt}$ was the obvious choice. Alternative catalysts that have been used, are composed of various oxides such as iron oxides promoted with bismuth oxide. These catalysts are inferior to platinum and have only been used in countries where platinum was not available. ${ }^{11}$

The catalyst is usually made up in the form of woven wire gauzes. The use of $\mathrm{Pt}-\mathrm{Rh}$ alloys instead of pure $\mathrm{Pt}$ results in much better mechanical properties of the gauze and a significant reduction of $\mathrm{Pt}$ loss during the process. ${ }^{1,8)}$ Handforth and Tilley examined the effect of increasing $\mathrm{Rh}$ content on the catalytic performance. ${ }^{1)}$ They found that the Pt loss decreases with increasing $\mathrm{Rh}$ content and that the conversion efficiency is much improved by the addition of $\mathrm{Rh}$.

The commercial synthesis of HCN is carried out with mixtures of $\mathrm{NH}_{3}, \mathrm{CH}_{4}$ and air on the same catalyst as that used for the nitric acid production (90 $\mathrm{wt} \% \mathrm{Pt}, 10 \mathrm{wt} \% \mathrm{Rh})$. The reaction is carried out at a temperature of about $1400 \mathrm{~K}$, which is more than 200 degrees higher than that used for the ammonia oxidation (about $1200 \mathrm{~K}$ ).

Filters have been used to recover platinum lost during the ammonia oxidation. Most of the nitric acid manufacture plants in Europe use now goldpalladium catchment gauzes to recover Pt lost from the catalysts. ${ }^{19)}$ In this way recoveries of about $50 \%$ of the gross losses are achieved. ${ }^{19}$ )

Changes in surface structure and composition of the Pt-Rh alloy catalysts during heating in ammoniaair mixtures have been studied with a range of techniques including SEM, EPMA, XPS, AES, FIM and atom-probe FIM. ${ }^{2-8)}$ After oxidation a stable $\mathrm{Rh}$ rich oxide layer is formed. ${ }^{2-8)}$ However, McCabe and Smith found under some conditions that the outer layers of the oxide may become enriched in $\mathrm{Pt}_{\mathrm{t}}{ }^{6)}$ This effect was ascribed to the redeposition of vapor-phase platinum oxide on the surface. The wires of a new catalyst gauze are essentially smooth. During their use in the plant etching occurs along grain boundaries. The etching process spreads into the interior of the grains and well-developcd facets appear. Deep etch-pits often with very regular shape are formed and after some time cauliflower-like growth appears. ${ }^{2-8)}$ It has been shown that the reconstructions are related to vapor transport of $\mathrm{Pt}\left(\right.$ as $\mathrm{PtO}_{2}$ ). Pielaszek found that a $\mathrm{Pt}-10 \% \mathrm{Rh}$ single crystal is much more resistant to etching than a pure Pt crystal. ${ }^{81}$

\section{Automotive Catalysts}

The current generation automotive catalysts are three-way catalysts designed for the simultaneous conversion of three automotive pollutants: CO, hydrocarbons (" $\mathrm{HC}$ ") and $\mathrm{NO}_{x}{ }^{.1,12)}$ The most essential components of the three-way catalysts are platinum and rhodium. The catalyst consists of a monolithic support in the form of a honeycomb composed of a high melting ceramic material. The walls are coated with a high surface "washcoat " consisting of alumina with a number of stabilizers and promoters added. The precious metals $\mathrm{Pt}$ and $\mathrm{Rh}$ are incorporated into the washcoat.

The exhaust emissions of CO, " $\mathrm{HC}$ " and NO vary strongly with the air-fuel ratio. Because the catalyst performance is at its best close to the stoichiometric air-fuel ratio (around 14.6), the catalyst system is equipped with a closed-loop emission control system with an oxygen sensor that tunes the carburetter. The overall catalytic reactions which are important for control of the exhaust emission are given by the following stoichiometric equations:

$$
\begin{aligned}
& 2 \mathrm{CO}+\mathrm{O}_{2} \rightarrow 2 \mathrm{CO}_{2} \\
& " \mathrm{HC} "+x \mathrm{O}_{2} \rightarrow y \mathrm{H}_{2} \mathrm{O}+z \mathrm{CO}_{2} \\
& 2 \mathrm{NO}+2 \mathrm{CO} \rightarrow \mathrm{N}_{2}+2 \mathrm{CO}_{2} \\
& 2 \mathrm{NO}+2 \mathrm{H}_{2} \rightarrow \mathrm{N}_{2}+2 \mathrm{H}_{2} \mathrm{O}
\end{aligned}
$$

The desired products are $\mathrm{N}_{2}, \mathrm{CO}_{2}$ and $\mathrm{H}_{2} \mathrm{O}$. These reaction products are thermodynamically favored at typical cxhaust temperatures (around $800 \mathrm{~K}$ ).

Platinum is an effective oxidation catalyst for the oxidation of $\mathrm{CO}$ and " $\mathrm{HC}$ ". However, for the reduction of nitric oxide this metal is less effective. ${ }^{11,12)}$ One undesired reaction product is ammonia formed according to the stoichiometric equation.

$$
2 \mathrm{NO}+5 \mathrm{H}_{2} \rightarrow 2 \mathrm{NH}_{3}+2 \mathrm{H}_{2} \mathrm{O}
$$

Unfortunately, the selectivity of $\mathrm{Pt}$ to promote the NO reduction to $\mathrm{N}_{2}$ rather than to $\mathrm{NH}_{3}$ is poor. Rhodium is the essential ingredient in the catalyst for the conversion of $\mathrm{NO}$ to $\mathrm{N}_{2}$.

Three-way catalysts used in the USA contain 1 to $2 \mathrm{~g}$ of noble metal in the weight ratio $\mathrm{Pt} / \mathrm{Rh}$ of $10 / 1$, if not lower $\mathrm{Pt}$. This ratio differs significantly from the mine ratio for these metals $(\mathrm{Pt} / \mathrm{Rh}$ is $16.5 / 1)$. It has been established that $\mathrm{Pt}$ and $\mathrm{Rh}$ can form alloys in the three-way catalyst. The present paper describes some of the properties of well defined Pt-Rh 
alloy surfaces.

\section{Surface Composition}

\subsection{In Vacuum}

$\mathrm{Pt}$ and $\mathrm{Rh}$ are completely miscible at all concentrations with a slightly negative (exothermic) enthalpy of mixing. Ordered phases have not been reported, although some studies may indicate the presence of some short range order. ${ }^{20)}$ Let us first summarize what we may expect from the theories of surface segregation.

The approach used in many surface composition calculations is the application of the so-called broken-

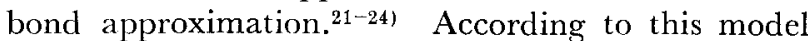
the surface is considered as a termination of the bulk with broken bonds with the missing neighbor atoms. The energy gain due to surface segregation is calculated assuming additivity of bond energies per pair of atoms. The binding energies of pairs of atoms $E_{\mathrm{AA}}$ and $E_{\mathrm{BB}}$ can be derived from the enthalpies of sublimation of the alloy components $\mathrm{A}$ and $\mathrm{B}$. The binding energy of a pair of $\mathrm{A}$ and $\mathrm{B}$ atoms can be calculated from $E_{\mathrm{AA}}, E_{\mathrm{BB}}$, the enthalpy of mixing $\Delta H_{\text {mix }}$ and the molar bulk fraction of $\mathrm{A}$ and $\mathrm{B}$. In the simplest model the ideal solution model, only the enthalpies of sublimation of both components are considered. It predicts surface enrichment of the component with the smaller enthalpy of sublimation. In the regular solution model corrections are made for $\Delta H_{\mathrm{mix}} \neq 0$. If the bulk mixing enthalpy is large and negative (exothermic) as for intermetallic compounds, the atoms $\mathbf{A}$ in the bulk favor an intimate contact with $\mathrm{B}$ atoms and vice versa. As a result, the system tends to attain a bulk composition with a maximum number of $\mathrm{A}-\mathrm{B}$ bonds $\left(\mathrm{AB}_{3}\right.$ and $\mathrm{A}_{3} \mathrm{~B}$ for the fcc and $\mathrm{AB}$ for the bcc structure) and, hence, the component present in excess segregates to the surface. However, if the bulk mixing enthalpy is large and positive (endothermic), large clusters of $\mathrm{A}$ and large clusters of $\mathrm{B}$ are formed and the component with the smaller enthalpy of sublimation segregates to the surface. A third effect that can influence the surface composition is that of the difference in atomic size of A and B. The lattice strain energy due to the difference in the size of atoms is lowered when the minority component is interchanged with the "solvent" component on the surface. Hence, these strain effects favor surface segregation of the minority component.

In all these models the principle factors affecting surface segregation are differences in bond strengths $(\mathrm{A}-\mathrm{A}, \mathrm{A}-\mathrm{B}$ and $\mathrm{B}-\mathrm{B})$ and atomic size. In addition, microscopic electronic theories have been proposed. An example is a recent paper of Mukherjee and Morán-Lopéz who presented a tight-binding electronic model using the $d$-band density of states of the constituent metals with bandwidth, band center and band filling as the input parameters. ${ }^{25}$

Table 1 shows some relevant parameters for $\mathrm{Pt}-\mathrm{Rh}$. It shows that the differences in heats of sublimations are very small ( 1 to $2 \%$ difference), $\mathrm{Pt}$ and $\mathrm{Rh}$ are nearly of the same size ( $\mathrm{Rh}$ is about $3 \%$ smaller than $\mathrm{Pt}$ ) and that the enthalpy of mixing is only slightly negative.

Fig. 1 shows the results of our calculations based on a Monte Carlo method. ${ }^{30)}$ The computed surface composition is almost equal to the bulk composition due to the almost equal values of the sublimation enthalpies and the atomic sizes of $\mathrm{Pt}$ and $\mathrm{Rh}$ in combination with the almost zero enthalpy of mixing.

Contrary to the predictions based on model calculations most of the experimental data point to a large Pt surface enrichment. Using LEISS, Williams and Nelson ${ }^{31}$ found that $\mathrm{Pt}$ segregates to the surface of polycrystalline $\mathrm{Pt}-\mathrm{Rh}$ alloys with a heat of segregation of $14 \mathrm{~kJ} / \mathrm{mol}$ in the temperature range $800-$ $1400 \mathrm{~K}$. That result is consistent with the interpretation of the AES analysis of Holloways and Williams ${ }^{32}$ ) for the (111) surface of a $\mathrm{Pt}_{0.1}-\mathrm{Rh}_{0.9}$ alloy equilibrated at $1100 \mathrm{~K}$ and of our own data obtained for the (100) and (410) surfaces of a $\mathrm{Pt}_{0.25}-\mathrm{Rh}_{0.75}$ single crystal. The temperature dependence of the surface composition is shown in Fig. 2. Van Langeveld and Niemantsverdriet ${ }^{34,35)}$ found for a polycrys-

Table 1. Relevant data of $\mathrm{Pt}, \mathrm{Rh}$ and $\mathrm{Pt}-\mathrm{Rh}$.

\begin{tabular}{lcccc}
\hline & Pt & Rh & Pt-Rh & Ref. \\
\hline$\Delta H^{\circ}$ subl. 298 (kJ/mol) & 565 & 557 & - & $26)$ \\
$r(\mathrm{~A})$ & 1.39 & 1.34 & - & - \\
$\theta_{D}(b)(\mathrm{K})$ & 234 & 350 & - & $27)$ \\
$\theta_{D}(s)(\mathrm{K})$ & $80^{*}$ & $160^{*}$ & - & $28)$ \\
$\Delta H_{\mathrm{mix}}(\mathrm{kJ} / \mathrm{mol})$ & - & - & $<0$ & $29)$ \\
\hline
\end{tabular}

* (111) surface

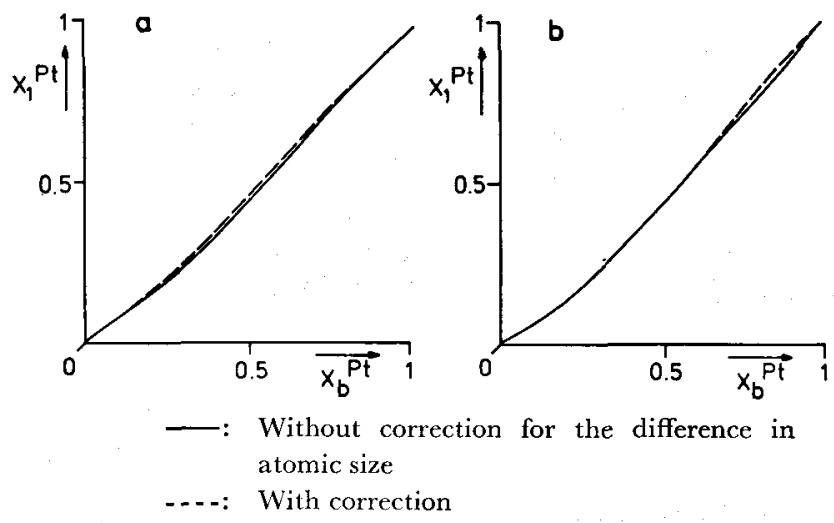

Fig. 1. Variation of the computed surface composition with bulk composition for (a) $\mathrm{Pt}-\mathrm{Rh}(111)$ and (b) $\mathrm{Pt}$ $\mathrm{Rh}(100)$ at $1100 \mathrm{~K}$. (from Ref. 30))

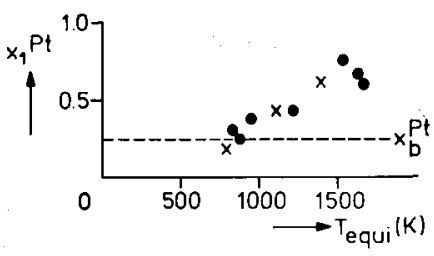

....: The bulk composition. (from Refs. 13) and 15))

$=(100), \quad x=(410)$

Fig. 2. Temperature dependence of the surface composition of $\mathrm{Pt}_{0.25}-\mathrm{Rh}_{\mathbf{0 . 7 5}}(100)$ and (410) faces. 
talline $\mathrm{Pt}_{0.6}-\mathrm{Rh}_{0.4}$ sample that has been equilibrated at $1000 \mathrm{~K}$ a $\mathrm{Pt}$ surface concentration of about $80 \%$. Using atom-probe FIM, Ahmad and Tsong ${ }^{36}$ ) found for the $(100)$ surface of a $\mathrm{Pt}-\mathrm{Rh}$ tip that $\mathrm{Rh}$ segregates to the top layer after annealing at $1000 \mathrm{~K}$. Later research of the same group showed that the Rh segregation was an effect of sulfur. ${ }^{37)}$ Although the bulk S content was less than 100 ppm, a S surface coverage of more than $20 \%$ of a monolayer was obtained.

In Fig. 3 composition depth profiles of two $\mathrm{Pt}_{\mathbf{0 . 5 5}^{-}}$ $\mathrm{Rh}_{0.45}$ alloys both having the same bulk composition, but one with $50 \mathrm{ppm} \mathrm{S}$, are shown. Obviously, Pt segregates to the top layer whereas the 2 nd layer is depleted of Pt. However, this segregation behavior is reversed when the crystal contains small amounts of $\mathrm{S}$.

Pt surface segregation is not confined to the closepacked surfaces since FEM observations of $\mathrm{Pt}-\mathrm{Rh}$ alloys suggest a Pt like behavior towards gases like nitrogen and carbon monoxide of the rough surfaces of a $\mathrm{Pt}_{0.5}-\mathrm{Rh}_{0.5}$ alloy and a strong $\mathrm{Pt}$ surface enrichment for $\mathbf{P t}_{0.12}-\mathrm{Rh}_{0.88}$ above $1500 \mathrm{~K} .{ }^{16)}$ Some results are shown in Fig. 4.

Fig. 4(a) illustrates that the apparent work function of the clean $\mathrm{Pt}_{0.12}-\mathrm{Rh}_{0.88}$ tip increases with increasing annealing temperature. This observation suggests again that the amount of surface $\mathrm{Pt}$ increases with increasing annealing temperature since the work function of $\mathrm{Pt}$ is about $0.5 \mathrm{eV}$ higher than that of a $\mathrm{Rh}$ field emitter. This effect is even better illustrated by the adsorption of nitrogen, as shown in Fig. 4(b). The work function change produced by nitrogen was measured as a function of the annealing temperature. Following annealing above $1200 \mathrm{~K}$ the work function change is equal to that found on pure Pt. The work function change found after annealing at 600-700 K is between the values found on pure $\mathrm{Rh}$ and pure $\mathrm{Pt}$. It suggests that the Pt surface concentration of atomically rough surfaces, as found on field emitters, increases with increasing annealing temperature. The

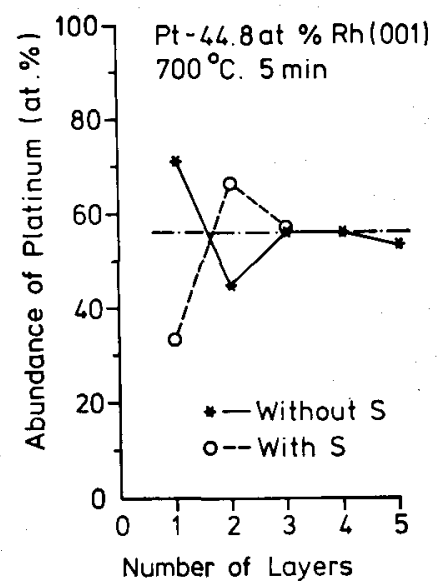

Fig. 3. Composition depth profile for the (100) surface of a high purity $\mathrm{Pt}_{0.55}-\mathrm{Rh}_{0.45}$ alloy cquilibrated at $1000 \mathrm{~K}$ and a same alloy but containing about 50 ppm of impurity sulfur. (from Ref. 37), with permission) largest change in surface composition occurs upon annealing around $1000 \mathrm{~K}$.

Summarizing we can conclude that the experimental data suggest that clean Pt-Rh alloy surfaces, both atomically rough and smooth surfaces, show a pronounced Pt surface enrichment that increases with increasing equilibration temperature. This temperature dependence is illustrated in Fig. 5. As we have discussed before, the Pt surface segregation can not be understood with the conventional surface segregation models. The small negative (exothermic) enthalpy of mixing can not be responsible for the $\mathrm{Pt}$ surface enrichment because $P t$ surface segregation is found both for $\mathrm{Pt}$ rich and $\mathrm{Rh}$ rich bulk compositions.
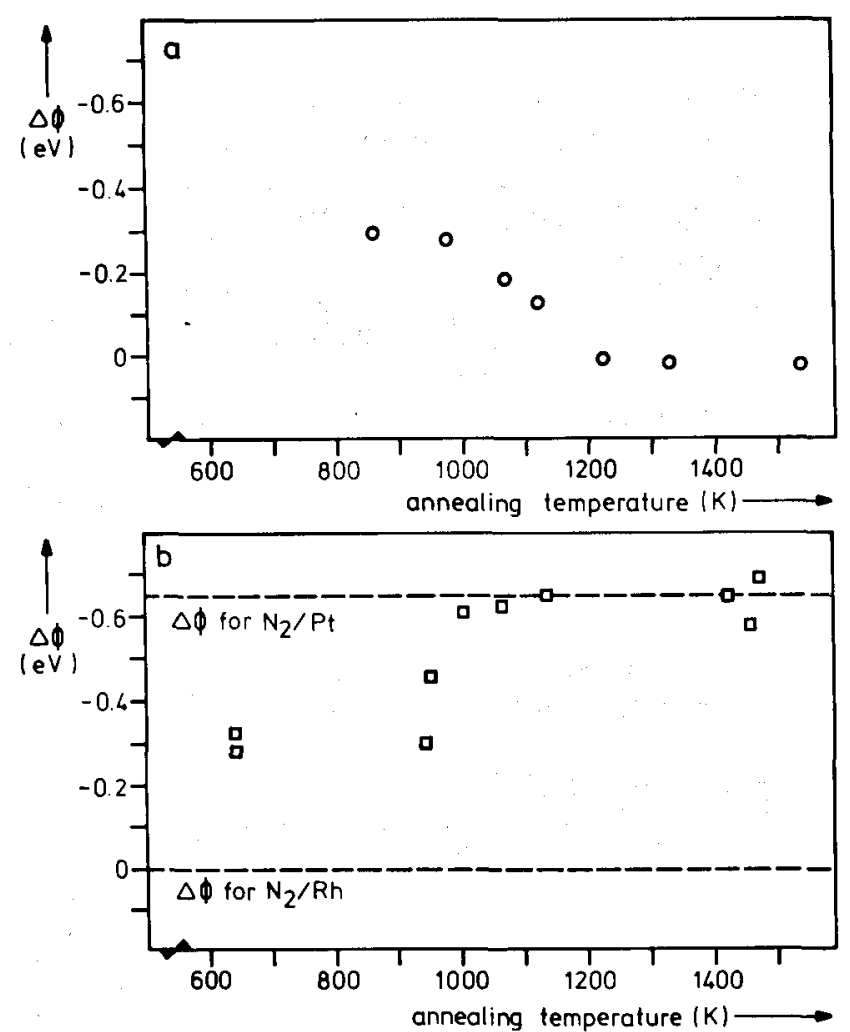

Fig. 4(a). Work function of a clcan $\mathrm{Pt}-\mathrm{Rh}$ tip at varying annealing temperatures, relative to the work function of the tip annealed at $1450 \mathrm{~K}$.

(b). Work function change as a result of nitrogenadsorption at $80 \mathrm{~K}$ at varying annealing temperatures. (from Ref. 16))

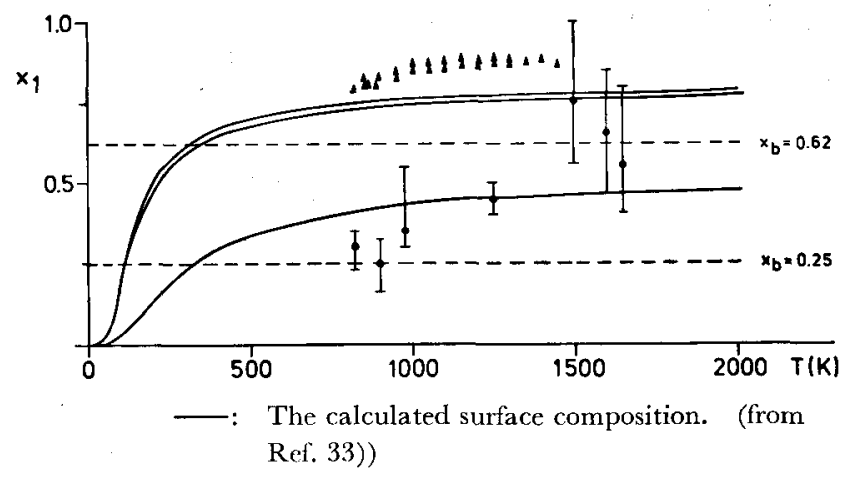

Fig. 5. The temperature dependence of the surface composition of (a) polycrystalline $\mathrm{Pt}_{0.62}-\mathrm{Rh}_{\mathbf{0 . 3 8}}$ ( $\mathbf{\Delta}$ ) and (b) $\mathrm{Pt}_{0.25}-\mathrm{Rh}_{0.75}(100)$ 
A possible model that can explain the Pt surface segregation has been put forward by Van Langeveld and Niemantsverdriet. ${ }^{34,35)}$ They noticed that the surface Debye temperature of $\mathrm{Pt}$ is extremely low compared to that of $\mathrm{Rh}$ and compared to the bulk Debye temperatures. The surface and bulk Debye temperatures represent the vibrational properties of the atoms on the surface and in the bulk, respectively. The values have been included in Table 1 . In the surface segregation models discussed so far the effect of lattice vibrations on the surface composition was neglected. Hoshino $^{38)}$ showed that the surface phonon softening (i.e., the Debye temperature is lower for the surface than for the bulk) may affect the surface composition of alloys. The reason is that surface segregation of the component with low surface Debye temperature leads to a larger entropy corresponding to the surface phonon. It should be noted that reliable values of the surface Debye temperature of $\mathrm{Pt}$ and $\mathrm{Rh}$ surfaces are not available and that the conventionally used method for determination of the surface Debye temperature is essentially not correct. ${ }^{28)}$ However, qualitatively the $\mathrm{Pt}$ surface segregation can be correctly predicted by the surface phonon softening model as is shown in Fig. 5. ${ }^{14,33}$

It should be pointed out that the pronounced $\mathbf{P t}$ surface segregation is not a definite proof that the surface phonon softening is the decisive factor. An interesting, alternative model that may explain the $\mathrm{Pt}$ surface segregation has been put forward for the explanation of $\mathrm{P} t$ surface segregation observed for $\mathrm{Pt}-\mathrm{Ni}$ alloys. This alloy is another example of the few alloy systems, whose surface segregation behavior can not be understood with the conventional surface segregation models. The models predict a $\mathrm{Ni}$ surface enrichment whereas several studies confirmed a pronounced Pt surface enrichment for the (111) surfaces of $\mathrm{Pt}-\mathrm{Ni}$ alloys. For example, Massadier et al. ${ }^{39,40)}$ reported a surface composition of $35 \pm 5 \% \mathrm{Pt}$ for $\mathrm{Pt}_{0.10}-\mathrm{Ni}_{0.90}$ (111) and a quasi complete $\mathrm{Pt}$ surface layer with less than 2-4\% $\mathrm{Ni}$ for $\mathrm{Pt}_{0.78}-\mathrm{Ni}_{0.22}$ (111) and $\mathrm{Pt}_{0.50}-\mathrm{Ni}_{0.50}(111)$. Spencer ${ }^{41)}$ suggested that the discrepancy between the calculated and the experimentally determined surface composition may be due to neglect of changes of bond energies due to surface relaxation. According to De Temmerman et al..$^{42)}$ the Pt surface enrichment is driven by a strengthening of the $\mathrm{Pt}-\mathrm{Pt}$ bonds in the surface region. This model is consistent with the adsorption behavior of the $\mathrm{Pt}-$ $\mathrm{Ni}$ (111) surfaces. It has been found that the heat of adsorption of several gases is significantly lower on the $\mathrm{Pt}-\mathrm{Ni}$ (111) surfaces than on the (111) surfaces of pure $\mathrm{Ni}$ and $\mathrm{Pt} .{ }^{39,40)}$ As we shall see such a weakening of the adsorption bond does not occur on $\mathrm{Pt}-\mathrm{Rh}$ surfaces. Moreover, the temperature dependence of the surface composition of $\mathrm{Pt}-\mathrm{Rh}$ alloys is completely in line with the earlier mentioned model based on surface phonon softening. Evidently, the surface phonon softening model predicts that the Pt surface concentration becomes larger with rising temperature because of the increasing importance of the entropy contributions to the free energy at higher tempera- ture. At lower temperatures the increasing importance of the enthalpy contributions results in a lowering of the Pt surface concentration as has indeed been observed. If the driving force for Pt surface segregation would be dominated by enthalpy contributions the surface excess of Pt must decrease with increasing temperature, whereas the opposite effect is observed. The peculiar surface segregation behavior of $\mathrm{Pt}-\mathrm{Rh}$ alloys is due to the very small differences in the binding energy parameters $\left(E_{\mathrm{Pt}-\mathrm{Pt}}, E_{\mathrm{kh}-\mathrm{Rh}}\right.$ and $\left.E_{\mathrm{Pt}-\mathrm{Rh}}\right)$. In consequence, the surface composition is extremely sensitive to the presence of adsorbate atoms. Any contaminant that has a slight preference for either $\mathrm{Pt}$ or Rh may induce surface segregation.

\subsection{In an Atmosphere of Reactive Gases}

It is known that the presence of a gaseous environment can modify the intrinsic surface segregation tendency of alloys. ${ }^{21,22,24)}$ As we have discussed before, $\mathrm{Pt}-\mathrm{Rh}$ alloys exposed to oxygen at elevated temperatures show $\mathrm{Rh}$ surface segregation., ${ }^{5,6)}$ In order to investigate the gas induced surface segregation in more detail several $\mathrm{Pt}-\mathrm{Rh}$ alloy single crystal surfaces were exposed to flows of several gases while the temperature was varied. ${ }^{17)}$ The surface analytical technique used was AES. First the temperature was increased in steps from 300 to $1200 \mathrm{~K}$ and then the temperature was decreased, again stepwise. For the interpretation of the AES results it is convenient to define the parameter $\delta$ :

$$
\begin{aligned}
\delta= & \frac{I(\mathrm{Pt} 64 \mathrm{eV})}{I \mathrm{Rh}(302 \mathrm{eV})}[\text { in vacuum }] \\
& -\frac{I(\mathrm{Pt} 64 \mathrm{eV})}{I(\mathrm{Rh} 302 \mathrm{eV})}[\text { in gaseous environment }],
\end{aligned}
$$

where, $I$ : the intensity of the relevant surface sensitive Auger signal.

Several processes may contribute to changes in $\delta$. For $\mathrm{Pt}-\mathrm{Rh}$ the major contributions are

$$
\begin{array}{ll}
\text { gas induced Rh surface segregation: } & \delta>0 \\
\text { selective adsorption on } \mathrm{Pt}: & \delta>0 \\
\text { gas induced Pt surface segregation: } & \delta<0 \\
\text { selective adsorption on Rh: } & \delta<0 .
\end{array}
$$

Some of the results are shown in Fig. 6 for Pt$\mathrm{Rh}(410)$ in an oxygen atmosphere of $5 \cdot 10^{-7} \mathrm{mbar}$. It can be concluded from the figure that at low temperature oxygen is selectively adsorbed on the $\mathrm{Rh}$ sites while heating in the oxygen atmosphere results in oxygen induced $\mathrm{Rh}$ surface segregation. This process is observed in the temperature range 600 to about $1000 \mathrm{~K}$. The oxygen induced $\mathrm{Rh}$ segregation is responsible for the fact that the maximum temperature at which oxygen is present on the surface does not depend on the equilibration temperature. The maximum in $\delta$ is related to the decrease in oxygen coverage above $800 \mathrm{~K}$. Oxygen desorbs from the surface above $800 \mathrm{~K}$, first from the Pt sites and as a result $\delta$ decreases above $800 \mathrm{~K}$.

Similar measurements have been performed in the presence of a flow of $5.10^{-7}$ mbar of $\mathrm{NO}, \mathrm{CO}$ and 

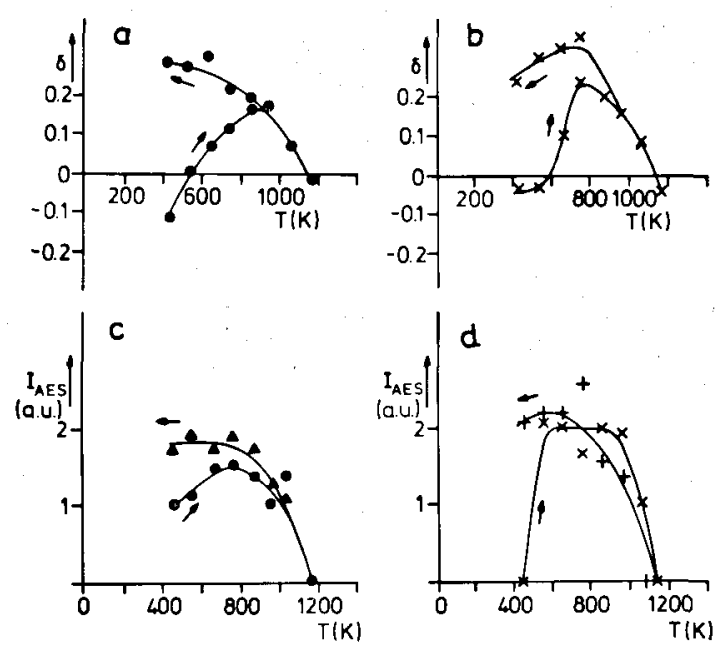

Fig. 6. AES results obtained for $\mathrm{Pt}-\mathrm{Rh}(410)$ in a flow of $5.10^{-7} \mathrm{mbar}_{2}$. $\delta$ as a function of the temperature for (a) Rh rich surface and (b) Pt rich surface. Auger $O$ signal intensity as a function of the temperature for (c) $\mathrm{Rh}$ rich surface and (d) Pt rich surface. (from Ref. 17))

$\mathrm{H}_{2}{ }^{17)}$ For $\mathrm{CO}$ and $\mathrm{H}_{2}$ the change in $\delta$ with increasing temperature was very small and, hence, these gases do not exert a significant influence on the surface composition. For NO a similar effect as for oxygen was observed but the induced surface segregation is much less pronounced than for $\mathrm{O}_{2}$. These results suggest that $\mathrm{NO}$ dissociates both on $\mathrm{Pt}$ rich and $\mathrm{Rh}$ rich alloy surfaces and the $\mathrm{O}$ formed can induce some oxygen induced surface segregation.

\section{Adsorption Properties}

The adsorption properties of several polycrystalline Pt-Rh foils, pure $\mathrm{Pt}$, pure $\mathrm{Rh}$ and of various single crystal surfaces cut from a $\mathrm{Pt}_{0.25}-\mathrm{Rh}_{0.75}$ single crystal have been investigated. ${ }^{15,17,18)}$ The comparison of the behavior of the various single crystal surfaces allows to examine the effect of the surface structure. The surface composition of the single crystal surfaces was varied from $\mathrm{Rh}$ rich to $\mathrm{Pt}$ rich simply by variation of the equilibration temperature. In this review paper only some of our results are presented. The techniques used were TDS, AES, XPS and LEED.

The adsorption of hydrogen and carbon monoxide is rather similar on all the $\mathrm{Pt}-\mathrm{Rh}$ alloy surfaces, as well as on the pure $\mathrm{Pt}$ and $\mathrm{Rh}$ surfaces. Both the surface structure and the surface composition exert some influence on the TD spectra and hence, on the heat of adsorption. These relatively small effects are, however, not relevant for the present discussion. No indication of $\mathrm{GO}$ dissociation was found.

Striking differences have been observed in the behavior of $\mathrm{Pt}$ rich and $\mathrm{Rh}$ rich alloys towards oxygen. As a first example Fig. 7 shows some AES results obtained for polycrystalline foils. After an exposure of $100 \mathrm{~L}$ the oxygen was pumped out the vacuum chamber and the $\mathrm{O}(510 \mathrm{eV})$ signal intensity was monitored during a stepwise increase of the temperature. In the figure the intensities normalized to their

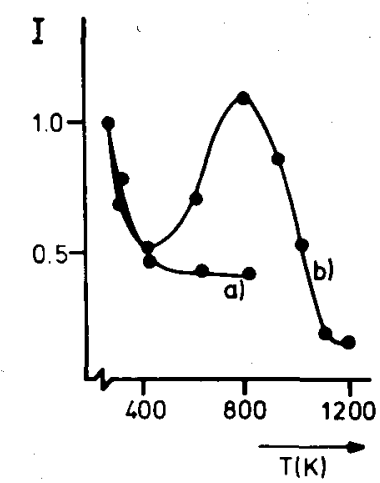

Fig. 7. Normalized $\mathrm{O}$ signal intensity as a function of the temperature for $100 \mathrm{~L} \mathrm{O}_{2}$ exposure on: (a) $\mathrm{Pt}$ and $\mathrm{Pt}_{\mathbf{0 . 5 5}}-\mathrm{Rh}_{0.45}$ and (b) $\mathrm{Pt}_{0.12}-\mathrm{Rh}_{0.88}$. (from Ref. 18))

initial values at $300 \mathrm{~K}$ are shown. The initial amount of oxygen on $\mathrm{Pt}$ rich alloys is much smaller than on $\mathrm{Rh}$ rich alloys. On $\mathrm{Pt}$ rich alloys the small oxygen signal disappears already at about $400 \mathrm{~K}$, probably by reaction with residual hydrogen and $\mathrm{CO}$ (Base pressure in the ultrahigh vacuum system was $1.10^{-9}$ Torr consisting of $90 \% \mathrm{H}_{2}$ and $10 \% \mathrm{CO}$ ). On $\mathrm{Rh}$ rich alloys the amount of surface oxygen decreases upon heating in the temperature range up to $500 \mathrm{~K}$, probably by reaction with the residual gas. However, above $500 \mathrm{~K}$ the oxygen surface concentration increases before it desorbs in the temperature range 800-1200 K. Apparently, subsurface oxygen is present in large amounts and it diffuses to the surface above $500 \mathrm{~K}$. Since the oxygen signal intensity becomes larger than the signal intensity at $300 \mathrm{~K}$, the subsurface oxygen must have been formed already at the exposure temperature of $300 \mathrm{~K}$. The $\mathrm{Pt}_{0.55}$ $\mathrm{Rh}_{0.45}$ sample shows a $\mathrm{Pt}$ like behavior. For the $\mathrm{Pt}_{0.12}-\mathrm{Rh}_{0.88}$ alloy either the $\mathrm{Pt}$ like or the $\mathrm{Rh}$ like behavior was observed depending on the experimental conditions. A similar ambivalent behavior has been found for the $\mathrm{Pt}_{0.25}-\mathrm{Rh}_{0.75}(100)$ surface. It appeared that subsurface oxygen is formed after low temperature annealing ( $975 \mathrm{~K}$, Rh rich surface) whereas high temperature equilibration (1 $425 \mathrm{~K}$, Pt rich surface) results in the $\mathrm{Pt}$ like behavior.

The effect of an exposure of 100L NO on the various samples was studied in the same way as described for oxygen. The behavior of the oxygen signal was identical to that found after exposure to oxygen for all samples. This indicates that NO dissociates on all surfaces leaving oxygen adatoms. The NO dissociation is partly due to the intrinsic chemical activity of the surface and, most probably, partly induced by the primary electron beam.

According to several studies, NO dissociation is very sensitive to the surface structure of $R h^{43)}$ and, in particular, of $\mathrm{Pt}^{44-46)}$ For example, it has been reported that the $\mathrm{Pt}(111)$ surface can not break the $\mathrm{NO}$ bond whereas the $\mathrm{Pt}(410)$ surface is very active in NO bond breaking. ${ }^{45)}$ In general, $\mathrm{Rh}$ is a better catalyst for NO dissociation than Pt. ${ }^{43}$ XPS has been used to investigate the NO dissociation on $\mathrm{Pt}$ Rh single crystal surfaces. ${ }^{15)}$ The results are sum- 


$\begin{array}{lc}T_{\text {equi }}(\mathrm{K}) & T_{\text {equi }}(\mathrm{K}) \\ (610) & (410) \\ (210) & -- \\ (321) & (210) \\ (111)-- & (321) \\ & (111)\end{array}$

$\mathrm{Rh}(410) \quad \cdots$
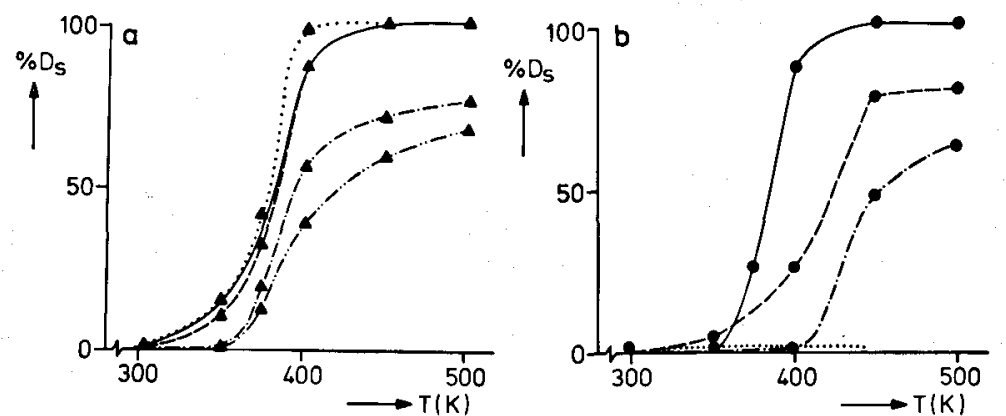

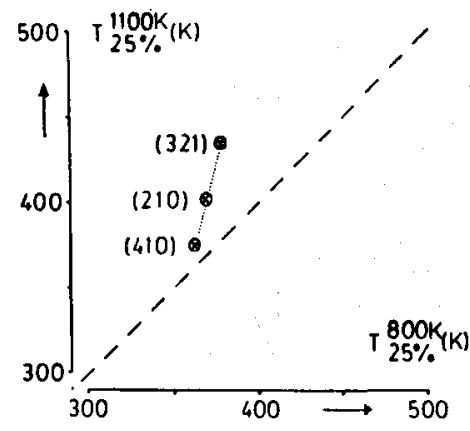

Fig. 9. The temperature at which a dissociation percentage of $25 \%$ is obtained for $\mathrm{Pt}$ rich $\mathrm{Pt}-\mathrm{Rh}$ alloy surfaces $v s$, the same parameter for $\mathrm{Rh}$ rich $\mathrm{Pt}-\mathrm{Rh}$ alloy surfaces. (from Ref. 15))

(a) Rh and $\mathrm{Rh}$ rich $\mathrm{Pt}-\mathrm{Rh}$ surfaces

(b) Pt rich Pt-Rh surfaces (from Ref. 15))

Fig. 8. The NO dissociation percentage as a function of the temperature for various $\mathrm{Pt}-\mathrm{Rh}$ surfaces.

marized in the Figs. 8 and 9. The figures show:

(1) The dissociation activity is sensitive to the surface structure. The (410) and (210) surfaces are more active in NO bond breaking than the (321) surface whose activity is larger than that of the (111) surface. The effect of the surface structure is larger for the $\mathrm{Pt}$ rich than for the $\mathrm{Rh}$ rich surfaces.

(2) The dissociation activity is higher for the $\mathrm{Rh}$ rich (equilibration at $800 \mathrm{~K}$ ) than for the $\mathrm{Pt}$ rich surfaces (equilibration at $1100 \mathrm{~K}$ ).

\section{CO Oxidation and NO Reduction}

In order to investigate the influence of the initial surface composition and of the gas induced surface segregation on the reactivity TPRMS and AES measurements have been performed in various gas mixtures of $\mathrm{CO}+\mathrm{O}_{2}$ and $\mathrm{CO}+\mathrm{NO}$ using the $\mathrm{Pt}-\mathrm{Rh}(410)$ surface.

Fig. 10 shows the $\mathrm{CO}_{2}$ production for the reaction of $\mathrm{CO}$ with $\mathrm{O}_{2}$ and for $\mathrm{CO}$ with $\mathrm{NO}$ starting with a $\mathrm{Pt}$ rich and with a $\mathrm{Rh}$ rich surface as observed during a stepwise increase of the temperature using stoichiometric gas compositions $\left(\mathrm{CO} / \mathrm{O}_{2}=2 / 1\right.$ and $\mathrm{CO} / \mathrm{NO}=$ 1). For comparison the Auger $\mathrm{N}(380 \mathrm{eV})$ and 0 $(510 \mathrm{eV})$ signal intensities as observed in a flow of $5.10^{-7} \mathrm{mbar} \mathrm{NO}$ are also shown in the figure. In the relevant temperature range $(500-800 \mathrm{~K}$ ) $\mathrm{NO}$ dissociation is very fast. The temperature of maximum $\mathrm{CO}_{2}$ production $\left(T_{m}\right)$ is the same for both reactions. Hence, it can be concluded that NO dissociation is not the rate determining step in the reaction $\mathrm{CO}+$ NO under our experimental conditions. This conclusion is consistent with the results described in Chap. 5.

The $\mathrm{Rh}$ rich surface shows a maximum rate of $\mathrm{CO}_{2}$ production around $665 \mathrm{~K}$. However, on the $\mathrm{Pt}$ rich surfaces the maximum occurs at the significantly lower temperature of $615 \mathrm{~K}$. Apparently, the surface composition has a significant influence on $T_{m}$. This can
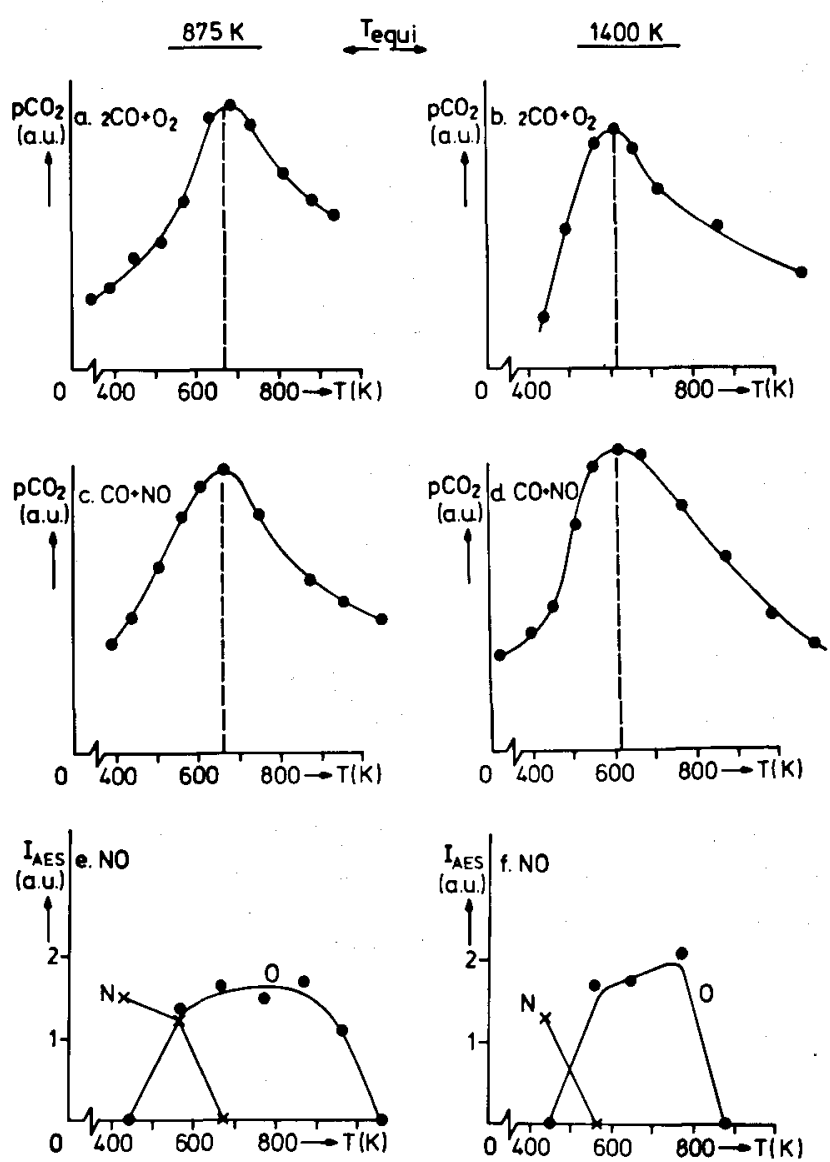

Fig. 10. TPRMS results for a stoichiometric flow of $\mathrm{CO}$ and $\mathrm{O}_{2}$.

(a) $\mathrm{Rh}$ rich $\mathrm{Pt}-\mathrm{Rh}(410)$; (b) $\mathrm{Pt}$ rich $\mathrm{Pt}-\mathrm{Rh}$ (410) and for a stoichiometric flow of $\mathrm{CO}$ and $\mathrm{NO}$; (c) $\mathrm{Rh}$ rich $\mathrm{Pt}-\mathrm{Rh}$ (410) and (d) $\mathrm{Pt}$ rich $\mathrm{Pt}-\mathrm{Rh}$ (410). Auger nitrogen and oxygen signal intensities in a flow of $5.10^{-7}$ mbar $\mathrm{NO}$ for (e) $\mathrm{Rh}$ rich $\mathrm{Pt}-\mathrm{Rh}$ (410) and (f) Pt rich Pt-Rh(410). (from Ref. 17))

be explained on the basis of the metal oxygen bond strength, ${ }^{47}$ which is weaker for $\mathrm{Pt}$ than for $\mathrm{Rh}$, as is also confirmed by the Figs. 10(e) and 10( $\mathrm{Y})$.

Fig. 11 shows the results of similar measurements for increasing, decreasing and again increasing tem- 
perature (1st, 2nd and 3rd branch, respectively). In the Ist branch $T_{m}$ is higher for the $\mathrm{Rh}$ rich surface, as has been discussed. The 2 nd branch shows a higher $\mathrm{CO}_{2}$ production, with $T_{m}$ almost similar for the two surfaces. The 3rd branch shows a higher $\mathrm{CO}_{2}$ production than the lst branch, but lower than the 2nd. $T_{m}$ is now equal for the initially $\mathrm{Rh}$ rich and $P t$ rich surfaces, and it is slightly higher than in the 2 nd branch and in between the values of the 1 st branch. Apparently, the surface composition alters during the reaction and is not dependent anymore on the initial equilibration temperature. AES measurements, not shown in this paper, support this conclusion. The largest changes occur on the initially $\mathrm{Rh}$ rich surface.

In the Figs. $11(\mathrm{c})$ and $11(\mathrm{~d})$ the $\mathrm{C}(272 \mathrm{eV})$ and $\mathrm{O}(510 \mathrm{eV})$ signal intensities are shown as a function of the temperature program. The product of the carbon and oxygen signal intensities is at a maximum in the same temperature region where the $\mathrm{CO}_{2}$ production is at a maximum, confirming the essential reaction step between $\mathrm{CO}(\mathrm{ads})$ and $\mathrm{O}(\mathrm{ads}) .{ }^{47)}$ The higher $\mathrm{CO}_{2}$ production in the 2nd branch might be expected if, starting at high temperatures, $\mathrm{O}_{2}$ is the 1st gas that will adsorb, whereas at low temperatures the surface is inhibited by excess $\mathrm{CO}$ (high sticking probability). However, the AES results in the Figs. 11 (c) and 11(d) do not support this model; here the carbon signal intensity is higher in the 2nd branch, especially for the initially $\mathrm{Rh}$ rich surface, whereas the oxygen signal intensity is smaller.

Apparently the enlarged $\mathrm{CO}_{2}$ production for the 2nd branch is due to a more favorable surface composition. Pt surface segregation can only take place
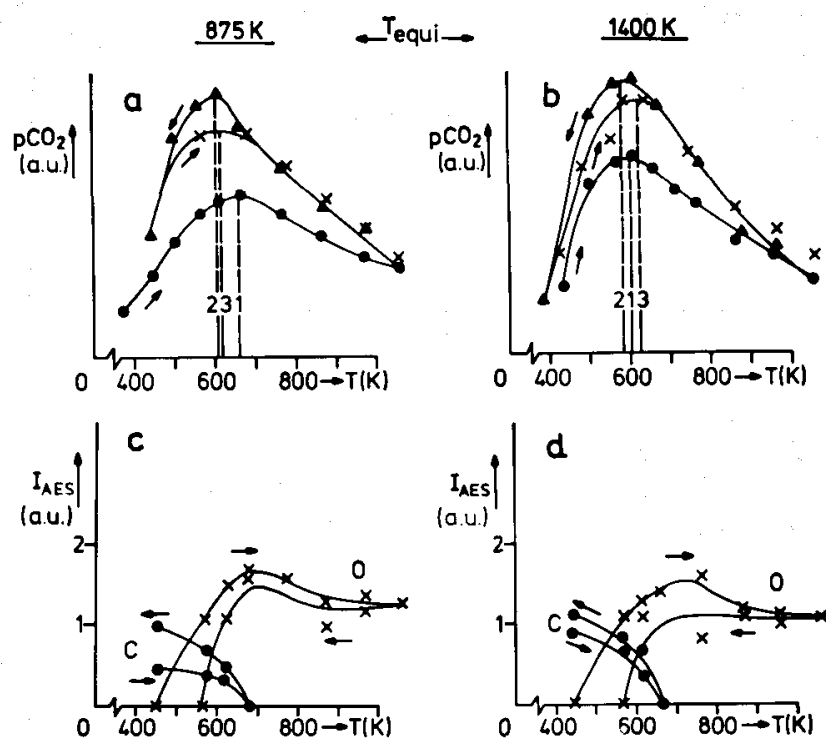

Fig. 11. TPRMS results for a stoichiometric flow of $\mathrm{CO}$ and $\mathrm{O}_{2}$.

(a) Rh rich Pt-Rh(410); (b) Pt rich Pt-Rh(410) with increasing (1), decreasing (2) and again increasing (3) temperature.

AES carbon and oxygen signal intensities in the same flow for (c) $\mathrm{Rh}$ rich $\mathrm{Pt}-\mathrm{Rh}(410)$ and (d) $\mathrm{Pt}$ rich $\mathrm{Pt}-\mathrm{Rh}(410)$. (from Ref. 17)) at high temperatures for low adsorbate coverages, if the $\mathrm{Pt}$ surface segregation is due to a vibrational entropy effect. Adsorbates may dim the vibrations and, hence, influence the segregation. Moreover, the enthalpy terms involved in the surface segregation process are rather small and, consequently a slight preference of an adsorbate for one of the components can seriously influence the surface composition. Another effect that should be considered for explanation of the enlarged $\mathrm{CO}_{2}$ production in the 2 nd branch is a difference in surface structure for rising and falling temperature in the gas mixture. Anyhow, the results presented in Fig. 11 suggest that the initial surface composition is altered by chemisorption induced segregation and/or thermal segregation effects.

In Fig. 12 the maximum $\mathrm{CO}_{2}$ production is shown as a function of the equilibration temperature, for the increasing and decreasing temperature branches in the various gas mixtures studicd. In general, with decreasing temperature the maximum $\mathrm{CO}_{2}$ production is higher than with increasing temperature. As discussed above, different adsorbate coverages can not be used to explain this difference for a stoichiometric $\mathrm{CO}+\mathrm{O}_{2}$ mixture. An adapted surface composition and, possibly, structural changes in the surface are responsible for this effect. The curves for decreasing temperature are slightly less pronounced than those for increasing temperature, indicating that the surfaces tend to attain the same final composition. The optimum initial and induced final surface composition appears to be $\mathrm{Pt}$-rich for stoichiometric and reducing gas mixtures and moderately $\mathrm{Pt}$ rich for slightly oxidizing gas mixtures. The curves in Fig. 12 show clear maxima for the alloy surfaces confirming the syn-
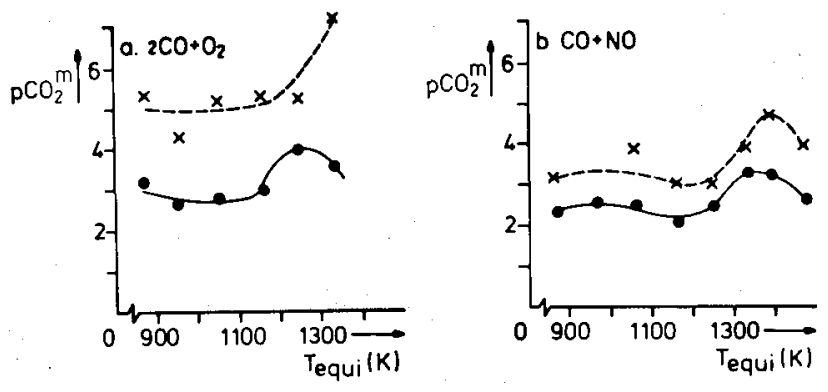

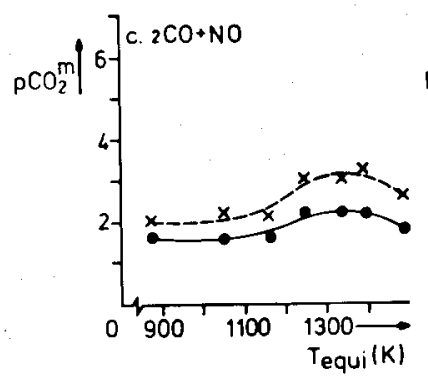

(a) $\mathrm{CO}+\mathrm{O}_{2}(2: 1)$

(b) $\mathrm{CO}+\mathrm{NO}(1: 1)$

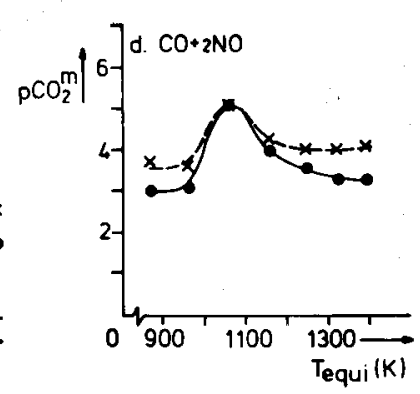

(c) $\mathrm{CO}+\mathrm{NO}(2: 1)$

(d) $\mathrm{CO}+\mathrm{NO}(1: 2)$
Fig. 12. The maximum $\mathrm{CO}_{2}$ production as a function of the equilibration temperature for increasing (-) and decreasing temperature branches (-..-) (from Ref. 17)). 
ergism as observed by $\mathrm{Oh}$ and Carpenter ${ }^{48)}$ for supported $\mathrm{Pt} / \mathrm{Rh}$ compared to pure $\mathrm{Pt}$ and pure $\mathrm{Rh}$. Dual selective chemisorption (oxygen on $\mathrm{Rh}$ sites and $\mathrm{CO}$ on $\mathrm{Pt}$ sites simultaneously), resulting in an optimum mixing of the reacting adsorbates on the surface might form a basic line of thought for understanding the reported synergism of alloying for the $\mathrm{CO}$ oxidation reaction.

\section{Concluding Remarks}

Bimetallic $\mathrm{Pt}-\mathrm{Rh}$ catalysts are used for two important processes: the purification of the exhaust gases from automobiles and the oxidation of ammonia for the production of nitric acid. This paper describes the composition and the chemical properties of $\mathrm{Pt}-$ $\mathrm{Rh}$ alloy surfaces in relation to these applications of Pt-Rh catalysts.

The alloy $\mathrm{Pt}-\mathrm{Rh}$ is unique in the sense that the binding energy parameters, $E_{\mathrm{Pt}-\mathrm{Pt}}, E_{\mathrm{Rh}-\mathrm{Rh}}$ and $E_{\mathrm{Pt}-\mathrm{Rh}}$ are virtually equal. Moreover, the vibrational entropy difference for surface segregation is relatively large. As a result, the surface composition of $\mathrm{Pt}-\mathrm{Rh}$ alloys is rather unique, and also flexible: it varies easily with changing experimental conditions (Temperature, gas phase composition). This has important consequences for the chemical behavior of $\mathrm{Pt}-\mathrm{Rh}$ catalysts. Strong Pt surface segregation is observed for clean $\mathrm{Pt}-\mathrm{Rh}$ alloys, especially after high temperature annealing $(7>1000 \mathrm{~K})$. However, for $\mathrm{Rh}$ rich $\mathrm{Pt}-\mathrm{Rh}$ alloys the surface composition is almost bulk like following low temperature equilibration ( $T \sim 800$ $\mathrm{K}$ ). Adsorbates can easily induce segregation of $\mathrm{Rh}$ or Pt to the surface and the chemical properties of the surface are changed accordingly.

It is tempting to speculate about the possible relevance of these results for automotive pollution control. It has been reported that bimetallic $\mathrm{Pt}-\mathrm{Rh}$ catalysts exhibit a synergetic effect towards $\mathrm{CO}$ oxidation. ${ }^{48)}$ Our results also indicate a beneficial effect of alloying $\mathrm{Pt}$ with $\mathrm{Rh}$ on the $\mathrm{CO}$ oxidation activity (Chap. 6). Moreover, alloying of $\mathrm{Rh}$ with Pt results in a higher stability in an oxidative atmosphere. ${ }^{49}$ ) $\mathrm{Pt}$ and $\mathrm{Rh}$ are most probably present in the form of Pt rich alloy particles in the three-way catalyst. The surface composition of the alloy particles will depend on the particle size, the temperature, the ambient composition and the presence of impurities. Under conditions of lean fuel-air mixtures (oxidizing mixture) a severe Rh surface enrichment must be expected, eventually leading to the formation of a less active $\mathrm{Rh}$ oxide on the surface of the catalyst particle. In this case the particle will show a catalytic behavior comparable with that of pure $\mathrm{Rh}$ although it will be more resistant to oxidation due to the presence of Pt. However, under rich conditions (reducing mixtures) a $\mathrm{Pt}$ rich surface is expected because of the Pt rich bulk. Hydrocarbon fragments and traces of impurities (P, S, Si, B) from the gasoline and from the lubricant may severely alter the surface composition and, consequently, modify the catalytic behavior of the alloy particles. Excursions to high tempera- ture (above $1000 \mathrm{~K}$ ) may result in a pronounced $\mathrm{Pt}$ surface segregation provided that the temperature is sufficiently high to obtain an uncovered surface. These considerations show that the surface composition of the catalyst particles in the three-way catalyst and, hence, the catalytic behavior of these particles may be very variable.

\section{Nomenclature}

AES: Auger Electron Spectroscopy

EPMA: Electron Probe Micro-Analysis

FEM: Field Electron Microscopy

FIM: Field Ion Microscopy

LEED: Low Energy Electron Diffraction

LEISS: Low Energy Ion Scattering Spectroscopy

SEM: Scanning Electron Microscopy

TDS: Thermal Desorption Spectroscopy

TPRMS: Temperature Programmcd Reaction Mass Spectroscopy

XPS: X-ray Photoelectron Spectroscopy

\section{Acknowledgements}

The authors would like to thank Dr. A. D. van Langeveld (Eindhoven Technical University), M. C. Angevaare-Gruter, M.J. Dees, M.J. Koster van Groos, R.J. Vreeburg and G. H. Vurens (Leiden University) for their valuable contributions.

\section{REFERENCES}

1) S. L. Handforth and J. N. Tilley: Ind. Eng. Chem., 26 (1934), 1287.

2) L. D. Schmidt and D. Luss: J. Catal., 22 (1971), 269 and refs. therein.

3) J. A. Busby and D. L. Trimm: J. Catal., 60 (1979), 430.

4) R. W. McCabe, T. Pignet and L. D. Schmidt: J. Catal., 32 (1974), 114.

5) T. Wang and L. D. Schmidt: J. Catal., 71 (1981), 411; 70 (1981), 187.

6) A. R. McCabe and G.D.W. Smith: Proc. 8th Int. Congr. Catal., Berlin, DECHEMA, Frankfurt, (1984), IV-73.

7) A. R. McCabe and G.D.W. Smith: Plat. Met. Rev., 32 (1988), 11.

8) J. Pielaszek: Plat. Met. Rev., 28 (1984), 109.

9) K. G. Gough and B. L. Wibberley: Plat. Met. Rev., 30 (1986), 168

10) Platinum 1988, Johnson Matthey Public Ltd. Co., London, (1988), 29, 59.

11) K. C. Taylor: Catal. Sci. Technol., J. R. Anderson and M. Boudart, ed., Springer, Berlin, 5 (1984), 119.

12) K. C. Taylor: "Catal. and Automotive Pollution Control", Stud. Surf. Sci. \& Catal., Vol. 30, A. Crucq and A. Frennet, ed., Elsevier, Amsterdam, (1987), 97.

13) F.G.M.J.M. van Delft and B. E. Nieuwenhuys: Surf. Sci., 162 (1985), 538.

14) F.C.M.J.M. van Delft, A. D. van Langeveld and B. E. Nieuwenhuys: Surf. Sci., 189/190 (1987), 1129.

15) F.C.M.J.M. van Delft, J. Siera, R. J. Vreeburg, M.J. Koster van Groos, A. D. van Langeveld and B. E. Nieuwenhuys: Proc. 9th Int. Congr. Catal., Calgary, Chem. Inst. Canada, Ottawa, (1988), 1114.

16) R. M. Wolf, M. J. Dees and B. E. Nieuwenhuys: J. Phys. Paris, 47 (C-7) (1986), 419/11.

17) F.C.M.J.M. van Delft, J. Siera and B. E. Nieuwenhuys: Surf. Sci, 208 (1989), 365. 
18) F.C.M.J.M. van Delft, G. H. Vurens, M. C. AngevaareGruter and B. E. Nieuwenhuys: "Catal. Automotive Pollution Control", Stud. Surf. Sci. \& Catal., Vol. 30, A. Crucq and A. Frennet., ed., Elsevier, Amsterdam, (1987), 229.

19) A. E. Heywood: Plat. Met.Rev., 26 (1982), 28.

20) H. J. Goldschmidt and T. Land: J. Iron Inst., 155 (1947), 221 and refs. therein.

21) H. J. Kelley and V. Ponec: Progr. Surf. Sci., 11 (1981), 139.

22) W.M.H. Sachtler and R. A. van Santen: Adv. Catal., 26 (1977), 69.

23) A. D. van Langeveld: Thin Solid Films, 129 (1985), 161.

24) B. E. Nieuwenhuys: "Chemisorption of Gases on Metal Films", Stud. Surf. Sci. \& Catal., Vol. 32, P. Wissmann, ed., Elsevier, Amsterdam, (1987), 476.

25) S. Mukherjee and J. L. Morán-Lopéz: Surf. Sci., 189/190 (1987), 1135.

26) M. Kh. Karapetyants and M. K. Karapetyants: Handbook of Thermodynamic Constants of Inorganic and Organic Compounds, Ann-Harbor-Humphrey Sci., Ann Harbor, (1970).

27) G. A. Somorjai: Chemisorption in Two Dimensions: Surfaces, Cornell Univ. Press, Ithaca, (1981).

28) F.C.M.J.M. van Delft, M. J. Koster van Groos, R.A.G. de Graaff, A. D. van Langeveld and B. E. Nieuwenhuys: Surf. Sci., 189/190 (1987), 695.

29) A. K. Niessen, F. R. de Boer, R. Boom, P. F. de Chatel, W.C.M. Matters and A. R. Miedema: Calphad, 7 (1983), 51.

30) G. H. Vurens, F.C.M.J.M. van Delft and B. E. Nieuwenhuys: Surf. Sci., 192 (1987), 438.

31) F. L. Williams and G. C. Nelson: Appl. Surf. Sci., 3 (1979),
409.

32) P. H. Holloway and F. L. Williams: Appl. Surf. Sci., 10 (1982), 1.

33) F.C.M.J.M. van Delft: Ph.D. Thesis, Leiden Univ., Leiden, (1988), Chapter XII, 162.

34) A. D. van Langeveld and J. W. Niemantsverdriet: Surf. Sci., 178 (1986), 880.

35) A. D. van Langeveld and J. W. Niemantsverdriet: J. Vac. Sci. Technol, $\mathbf{A 5}$ (1987), 558.

36) M. Ahmad and T. T. Tsong: J. Chem. Phys., 83 (1985), 388.

37) T. T. Tsong: Surf. Sci. Rep., 8 (1988), 127.

38) K. Hoshino: J. Phvs. Soc. Japan, 50 (1981), 577.

39) J. Massardier, B. Tardy, P. Delichère, M. Abon and J. C. Bertolini: Proc. 8th Int. Congr. Catal, Berlin, DECHEMA, Frankfurt, (1984), IV-185.

40) J. C. Bertolini, B. Tardy, M. Abon, J. Billy, P. Delichere and J. Massardier: Surf. Sci, 135 (1983), 117.

41) M. S. Spencer: Surf. Sci., 145 (1984), 153.

42) L. De Temmerman, G. Creemers, H. van Hove and A. Neyens: Surf. Sci., 183 (1987), 565.

43) H.A.C.M. Hendrickx and B. E. Nieuwenhuys: Surf. Sci., 175 (1986), 185.

44) R. J. Gorte, L. D. Schmidt and J. L. Gland: Surf. Sci., 109 (1981), 367.

45) R. I. Masel: Catal. Rev.-Sci. Eng., 28 (1986), 335.

46) P. Leerkamp, R. M. Wolf and B. E. Nieuwenhuys: $J$. Phys. Paris, 49 (C-6) (1988), 227.

47) B. E. Nieuwenhuys: Surf. Sci., 126 (1983), 307.

48) S. H. Oh and J. E. Carpenter: J. Catal., 98 (1986), 178.

49) A.J.S. Chowdhury, A. K. Cheetham and J. A. Cairns: J. Catal., 95 (1985), 253. 